\title{
Comparative Evaluation of Apical Transportation and Centering Ability of 4 NITI Rotary Systems with Different Metallurgy in Severely Curved Root Canals
}

\section{Ehab Abdel Hamid*}

Lecturer of Endodontics, Faculty of Oral and Dental Medicine, El Minya University, Egypt

*Corresponding Author: Ehab Abdel Hamid, Lecturer of Endodontics, Faculty of Oral and Dental Medicine, El Minya University, Egypt.

Orcid ID: https://orcid.org/0000-0002-8876-6582
Received: November 23, 2020

Published: December 09, 2020

(C) All rights are reserved by Abdel Hamid E.

\begin{abstract}
Objective: The aim of the present study was to compare apical transportation and centering ability of one curve (OC) system with other heat treated NiTi rotary systems; Protaper next (PTN), Hyflex EDM (HFEDM) and 2shape (TS), using CBCT scanning.

Methodology: Forty mesiobuccal canals of mandibular molars with an angle of curvature ranging from $\left(25^{\circ}-40^{\circ}\right)$ were divided equally according to file system used in canal preparation into 4 groups of 10 samples each: PTN group; HFEDM group, TS group and OC group. Samples were scanned using CBCT scanner before and after preparation to evaluate root canal transportation and centering ratio at 2, 3, 4 and $5 \mathrm{~mm}$ from the apex. The significance level was set at $\mathrm{P} \leq 0.05$.

Results: PTN showed highest statistically significant transportation value than other file systems at $5 \mathrm{~mm}$ level. There was no statistically significant difference in transportation between HFEDM, TS and OC file systems at all studied levels. There was no statistically significant difference in centering ability between 4 systems at 2, 3 and $4 \mathrm{~mm}$. At $5 \mathrm{~mm}$ level, OC and TS showed better centering ability than PTN and HFEDM.

Conclusion: The four tested systems safely prepared severely curved root canals, PTN showed highest transportation value and least centering ratio value, while HFEDM, TS and OC showed similar performance.
\end{abstract}

Keywords: ProTaper Next; HyFlex EDM; 2Shape; One Curve; Transportation; Centering Ability

\section{Introduction}

Root canal preparation is the most critical step to achieve objectives of root canal treatment. It includes mechanical debridement, creation space to deliver irrigants and optimized root canal shape for obturation while maintaining original root canal anatomy [1,2].

However, complexity and variation of root canal anatomy represent a major challenge that may jeopardize achieving objectives of root canal preparation and so successful root canal treatment. Preparation of curved root canals with inflexible conventional stainless-steel instruments, usually results in transportation and sebsequent procedural errors [3]. The introduction of super elastic highly flexible nickel titanium (Ni-Ti) instruments has revolution- ized root canal treatment that allow fast and safe preparation in curved root canals with less procedural errors [4-6].

Despite flexibility of these instruments, transportation and other procedural errors may occur especially in severely curved canals [7]. Several strategies were developed to improve their clinical performance in complex root canal anatomy, these strategies included change in design, surface treatment, kinematics and modifications in conventional NiTi alloy metallurgy via heat treatment $[8,9]$.

ProTaper Next (PTN; Dentsply Maillefer, Ballaigues, Switzerland) is the successor of the ProTaper Universal system (Dentsply Maillefer), in addition to progressive taper design, it is manufactured from heat treated alloy M-Wire which have higher flexibil- 
Comparative Evaluation of Apical Transportation and Centering Ability of 4 NITI Rotary Systems with Different Metallurgy in Severely Curved Root Canals

ity and better mechanical properties than conventional NiTi alloy [10-12]. Also, PTN has unique off-centered design, rectangular cross section which gives file strength and unique swaggering movement. The system composed of; X1 (17/.04), X2 (25/.06), X3 (30/.07), X4 (40/.06), and X5 (50/.06), and the tapers are variable (increasing and then decreasing in the apico- coronal direction for $\mathrm{X} 1$ and X2, fixed and then decreasing for X3, X4, and X5) [13]. These unique properties give the files high flexibility and resistance to cyclic fatigue $[14,15]$.

HyFlex EDM (HFEDM; Coltene/Whaledent, Altst€atten, Switzerland) is made from CM-Wire (controlled memory) which is a unique highly flexible wire without the shape memory of conventional NiTi alloy, allowing the instruments to be pre-bent with greater fatigue resistance $[16,17]$. It was the first system that produced by electrical discharge machining. its design is characterized by a variable cross section, with a transition from roughly triangular near the shaft to rectangular at the tip. This system consists of: 25/.12 (Orifice Opener), 10/.05 (Glidepath File), 25/.08 (OneFile), $40 / .04,50 / .03$, and 60/.02. The OneFile has a .08 taper in its apical $4 \mathrm{~mm}$, which decreases to .04 along the file. These unique features produced a file that is extremely flexible, has uniquely hardened surface and highly resistance to fracture [18-20].

2Shape (TS; MicroMega, Besancon, France) is manufactured with a different proprietary heat treatment called T-Wire technology which according to manufacturer increased flexibility and gave up to $40 \%$ more resistance to cyclic fatigue [21]. It consists of two instruments (\#25/.04 and \#25/.06), plus two options for wider canals (\#35/.06 and \#40/.04), with a new triple helix asymmetric cross-section design [22].

In 2017, Micro-Mega has developed the One Curve (OC; Besançon, France) single file system. According to the manufacturer, these instruments are exclusively manufactured from C-Wire using unique proprietary heat treatment which produced instruments with controlled memory, pre-bendable, more flexibile and highly resistance to fracture [23]. It is a single file rotary system with variable cross-section, available in different tip diameter and taper (\#25/.04, \#25/.06, \#35/.04 and \#45/.04) [24].

To date only one study that evaluated shaping ability of OC system, which was in moderately curved root canals [25]. Therefore, the aim of the present study was to evaluate transportation and centering ability of OC compared to other heat treated NiTi rotary systems (PTN, HFEDM, TS) in apical and middle thirds of severely curved root canals using cone-beam computed tomography (СВCT) scanning.

\section{Methodology}

Samples selection and preparation

Extracted human mandibular permanent first molars were collected from department of oral surgery, faculty of dentistry, El Minia university, which were extracted due to reasons unrelated to the present study.

Teeth were radiographed in both mesiobuccally and buccolingually, only teeth that have fully developed roots, separate mesial canals with separate foramina, root curvature ranged from $\left(25^{\circ}\right.$ $40^{\circ}$ ) according to Schneider's method [26] were selected. Any teeth that had calcification, root resorption, or previous root canal treatment were excluded.

Based on these selection criteria, a pilot study was performed to calculate sample size using G*Power Version 3.1.9.2. Three samples were included in each group and transportation was the primary outcome. The effect size (f) $=0.236$ was obtained using repeated measures within-between design test with variance within group $=0.9$ and variance between groups $=0.05$. Using alpha $(\alpha)$ level of $(5 \%)$ and Beta $(\beta)$ level of $(20 \%)$ i.e. power $=(80 \%)$; the minimum estimated sample size was a total of (40) samples.

Teeth were accessed by an Endo- Access bur (Dentsply Maillefer), and the meisobuccal canals were explored, localized and root canals patency was confirmed with a K-file size \#10 (Dentsply Maillefer). Distal roots with the respective part of the crown were sectioned at the furcation level using a low-speed diamond disc under copious irrigation, then discarded.

The working length was determined by inserting \#10 K-file into the root canal until the tip of the file was visible through the apical foramen then subtracting $0.5 \mathrm{~mm}$ from this measurement. The mesiobuccal cusp tip of all samples were reduced using high speed diamond fissure stone (Mani Inc., Tochigi-kan, Japan) with coolant to secure the reference point and obtain similar working length in all samples.

Samples were coded and randomly divided into four equal experimental groups ( $\mathrm{n}=10$ per group) according to the rotary NiTi file system used in canal preparation; PTN group ; HFEDM group, TS group and OC group. 
Comparative Evaluation of Apical Transportation and Centering Ability of 4 NITI Rotary Systems with Different Metallurgy in Severely Curved Root Canals

The degree of homogeneity between the groups regarding the angle of curvature was assessed and confirmed statistically.

\section{Samples scanning}

To ensure standardization of pre and postoperative CBCT scanning, samples were mounted vertically in transparent chemical cured acrylic resin mold (Acrostone, Dental and Medical Supplies, Cairo, Egypt) in which they were aligned to be perpendicular to the scanning beam with the buccal surface facing the same direction. The root apices were sealed with wax to prevent acrylic resin penetration. An orthodontic wire was placed buccally into the resin mold to enable canal orientation during image analysis.

Samples were scanned using a Paxi 3D Green CBCT scanner (VATECH Co, Ltd, Gyeonggi, South Korea). Exposure parameters were $80 \mathrm{kV}$ and $8 \mathrm{~mA}$. The field of view had a $12 \mathrm{~cm}$ diameter and was $9 \mathrm{~cm}$ high. voxel size was $0.2 \mathrm{~mm}$. The acquired data were viewed, and measurements were performed by the software OnDemand 3D (Cybermed, Seoul, South Korea).

\section{Root preparation}

All files were operated by a 1:16 gear reduction handpiece powered by an electric torque control motor (MM-control; MicroMega). A glide path was secured by a manual stainless steel \#10 K-file (Dentsply Maillefer). Each canal was prepared to the working length in a crown-down sequence and the final apical preparation was set to size 25 in each group. Each NiTi rotary file system was used according to the manufacturers' recommendations $[13,18,22,24]$ as follows.

- Group I (PTN): The canals were prepared using PathFile (16/02) followed by PTN X1 (17/04), then PTN X2 (25/06) to the full working length at $300 \mathrm{rpm}$ speed and $2 \mathrm{Ncm}$ torque.

- Group II (HEDM): The coronal third of canals were prepared using orifice opener (25/.12), followed by the glide path file (10/05) to the working length, and final preparation with HyFlex OneFile (25/ ) at $400 \mathrm{rpm}$ speed and 2.5 Ncm torque.

- $\quad$ Group III (TS): The coronal third of canals were prepared using one flare file (25/09) followed by TS1 (25/04) and TS2 $(25 / 06)$ files to the full working length at $300 \mathrm{rpm}$ speed and $2.5 \mathrm{Ncm}$ torque.

- Group IV (OC): The coronal third of canals were prepared using one flare file (25/09) followed by the OC file (25.06) to the full working length at $300 \mathrm{rpm}$ speed and $2.5 \mathrm{Ncm}$ torque.
Between each file size, copious irrigation with $3 \mathrm{~mL} 2.5 \% \mathrm{NaOCl}$ (Clorox, Egyptian company for house detergents, 10th of Ramadan, A.R.E) was performed using a 30-gauge max-i-Probe needle tips (Dentsply-Rinn, Elgin, IL, Switzerland) placed as apical as possible into the canal without binding. Patency was maintained using a size \#10 K-file. Each instrument was discarded after use in 5 canals.

After preparation, all canals were rinsed with $3 \mathrm{ml}$ distilled water, followed by $5 \mathrm{ml}$ 17\% EDTA (PREVEST Dent Pro, Indea) for 1 minute and final flush with $3 \mathrm{ml}$ distilled water. Subsequently, the samples were dried with absorbent paper points and submitted to postoperative scans using the same parameters described in the initial scanning and data were analyzed.

Image analysis and evaluation

After root canal instrumentation, samples were scanned under the same conditions and parameters as pre-instrumentation.

Canal transportation and centering ability were calculated at 4 cross sections levels according to the distance from the root apex; $2 \mathrm{~mm}, 3 \mathrm{~mm}$ (Representing the apical third) and $4 \mathrm{~mm}, 5 \mathrm{~mm}$ (Representing the middle third) using equations provided by Gambill., et al. (1996) [27] (Figure 1).
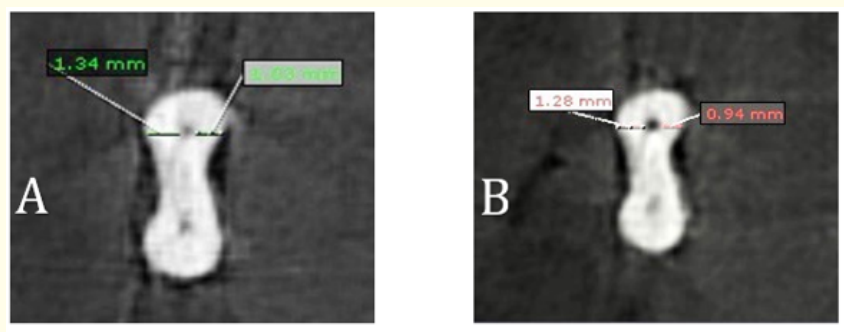

Figure 1: CBCT image at $5 \mathrm{~mm}$; A: pre-instrumentation measurements, B: post-instrumentation measurements.

For canal transportation

(M1-M2) - (D1-D2); in which a value equal to 0.0 indicated the absence of transportation.

For centering ratio

(M1-M2) / (D1-D2); in which a value of 1 indicated the optimal centering ability, whereas the closer the value to 0 , the more reduced the ability of the instrument to remain in a central position within the root canal. 
Comparative Evaluation of Apical Transportation and Centering Ability of 4 NITI Rotary Systems with Different Metallurgy in Severely Curved Root Canals

M1 is the shortest distance from the mesial edge of the root to the mesial edge of the uninstrumented canal, M2 is shortest distance from the mesial edge of the root to the mesial edge of the instrumented canal, D1 is the shortest distance from the distal edge of the root to the distal edge of the uninstrumented canal, and D2 is the shortest distance from the distal edge of the root to the distal edge of the instrumented canal.

\section{Statistical analysis}

Numerical data obtained were explored for normality by checking the distribution of data and using tests of normality (Kolmogorov-Smirnov and Shapiro-Wilk tests). All data showed non-normal (non-parametric) distribution. Therefore, data were presented as median and range values. Kruskal-Wallis test was used to compare between the four systems. Friedman's test was used to compare between different root levels. Dunn's test was used for pair-wise comparisons. The significance level was set at $\mathrm{P}$ $\leq 0.05$. Statistical analysis was performed with IBM SPSS Statistics for Windows, Version 23.0. Armonk, NY: IBM Corp.

\section{Results}

The median and range values of transportation and the center- ing ratio of all experimental groups at the four studied levels, are presented in table (1), and table (2) respectively.

\section{Transportation}

At two, three as well as four mm levels; there was no statistically significant difference between the four experimental groups, in which the highest median value of transportation ( 0.14 ) ) was recorded by PTN at $4 \mathrm{~mm}$, while the lowest median value of transportation ( 0.01 ) was recorded by HFEDM at $2 \mathrm{~mm}$ and TS at $3 \mathrm{~mm}$.

At five mm root level PTN recorded highest median value of transportation (0.15) which was statistically significant than other experimental groups (HFEDM, TS, OC). There was no statistically significant difference between HFEDM, TS, OC at this level in which OC recorded the lowest median value of transportation (0.04).

Regardless of root level as overall median values of transportation in four experimental groups, PTN recorded highest median value of transportation (0.11) which was statistically significant different than other groups. HFEDM, TS and OC; showed lowest median values of transportation; (0.04), (0.05), (0.05) respectively, which wasn't statistically significantly different.

\begin{tabular}{|c|c|c|c|c|c|c|c|c|c|c|}
\hline \multirow[t]{2}{*}{ Root level } & \multicolumn{2}{|c|}{$\begin{array}{c}\text { ProTaper Next } \\
(n=10)\end{array}$} & \multicolumn{2}{|c|}{$\begin{array}{c}\text { Hyflex EDM } \\
(n=10)\end{array}$} & \multicolumn{2}{|c|}{$\begin{array}{l}\text { 2Shape } \\
(n=10)\end{array}$} & \multicolumn{2}{|c|}{$\begin{array}{l}\text { One Curve } \\
(n=10)\end{array}$} & \multirow[t]{2}{*}{ P-value } & \multirow{2}{*}{$\begin{array}{c}\text { Effect } \\
\text { size (Eta } \\
\text { Squared) }\end{array}$} \\
\hline & Median & Range & Median & Range & Median & Range & Median & Range & & \\
\hline $3 \mathrm{~mm}$ & 0.07 & $0.01-0.1$ & 0.06 & $0-0.08$ & 0.01 & $0-0.12$ & 0.06 & $0.01-0.1$ & 0.745 & 0.049 \\
\hline $4 \mathrm{~mm}$ & 0.14 & $0.01-0.19$ & 0.05 & $0.04-0.12$ & 0.07 & $0-0.23$ & 0.05 & $0.03-0.09$ & 0.217 & 0.04 \\
\hline P-value & \multicolumn{2}{|c|}{0.090} & \multicolumn{2}{|c|}{0.888} & \multicolumn{2}{|c|}{0.073} & \multicolumn{2}{|c|}{0.063} & & \\
\hline Effect size (w) & \multicolumn{2}{|c|}{0.216} & \multicolumn{2}{|c|}{0.021} & \multicolumn{2}{|c|}{0.232} & \multicolumn{2}{|c|}{0.177} & & \\
\hline Overall & $0.11^{\mathrm{A}}$ & $0.05-0.12$ & $0.04^{\text {в }}$ & $0.03-0.1$ & $0.05^{\text {в }}$ & $0.05-0.18$ & $0.05^{\mathrm{B}}$ & $0.02-0.07$ & $0.009^{*}$ & 0.241 \\
\hline
\end{tabular}

Table 1: The median, range values and results of Kruskal-Wallis test for comparison between amounts of canal transportation (mm) after using different systems and Friedman's test for comparison between different root levels

*: Significant at $\mathrm{P} \leq 0.05$. A,B superscripts in the same row indicate statistically significant difference between systems.

\section{Centering ratio}

At two, three as well as four mm levels; there was no statistically significant difference between the four experimental groups in the median values of centering ratio, in which the highest median value of centering ratio (0.92) was recorded by HFEDM at $2 \mathrm{~mm}$ and by
TS at $3 \mathrm{~mm}$ while PTN showed the lowest median value $(0.39)$ at $4 \mathrm{~mm}$.

At five mm root level TS and OC systems showed the highest median value of centering ratio $(0.74),(0.75)$ respectively, which was statistically significant different than PTN and HFEDM. There 
Comparative Evaluation of Apical Transportation and Centering Ability of 4 NITI Rotary Systems with Different Metallurgy in Severely Curved Root Canals

was no statistically significant difference between PTN and HFEDM in which PTN showed the lowest median value $(0.46)$ of centering ratio.
Regardless of root level as overall median values of centering ratio; there was no statistically significant difference between the four systems.

\begin{tabular}{|c|c|c|c|c|c|c|c|c|c|c|}
\hline \multirow[t]{2}{*}{ Root level } & \multicolumn{2}{|c|}{$\begin{array}{l}\text { ProTaper Next } \\
\qquad(n=10)\end{array}$} & \multicolumn{2}{|c|}{$\begin{array}{c}\text { Hyflex EDM } \\
(n=10)\end{array}$} & \multicolumn{2}{|c|}{$\begin{array}{l}\text { 2Shape } \\
(n=10)\end{array}$} & \multicolumn{2}{|c|}{$\begin{array}{c}\text { One Curve } \\
(n=10)\end{array}$} & \multirow[t]{2}{*}{ P-value } & \multirow{2}{*}{$\begin{array}{c}\text { Effect } \\
\text { size (Eta } \\
\text { Squared) }\end{array}$} \\
\hline & Median & Range & Median & Range & Median & Range & Median & Range & & \\
\hline $3 \mathrm{~mm}$ & 0.61 & $0.29-0.91$ & 0.56 & $0.5-1$ & 0.92 & $0.29-1$ & 0.59 & $0.38-0.91$ & 0.229 & 0.037 \\
\hline $4 \mathrm{~mm}$ & 0.39 & $0.24-0.91$ & 0.55 & $0.37-0.69$ & 0.53 & $0.28-1$ & 0.71 & $0.43-0.75$ & 0.182 & 0.052 \\
\hline P-value & \multicolumn{2}{|c|}{0.112} & \multicolumn{2}{|c|}{0.682} & \multicolumn{2}{|c|}{0.540} & \multicolumn{2}{|c|}{0.051} & & \\
\hline Effect size (w) & \multicolumn{2}{|c|}{0.2} & \multicolumn{2}{|c|}{0.05} & \multicolumn{2}{|c|}{0.072} & \multicolumn{2}{|c|}{0.115} & & \\
\hline Overall & 0.56 & $0.5-0.66$ & 0.65 & $0.49-0.74$ & 0.72 & $0.31-0.82$ & 0.71 & $0.57-0.86$ & 0.101 & 0.09 \\
\hline
\end{tabular}

Table 2: The median, range values and results of Kruskal-Wallis test for comparison between centering ratio (CR) after using different systems and Friedman's test for comparison between different root levels

*: Significant at $\mathrm{P} \leq 0.05$. A,B superscripts in the same row indicate statistically significant difference between systems

\section{Discussion}

Root canal transportation was simply defined as "any undesirable deviation from natural canal paths" which resulted in many procedural errors; Zip-and-elbow formation, ledges, strip-perforations, or excessive thinning of canal walls [28]. Transportation and subsequent procedural errors result in improperly cleaned canals with persistent infection or thinning canal walls with possibility of perforation or vertical fracture [29,30]. Several factors affect incidence of transportation; root canal anatomy, file design, alloy of root canal instruments and instrumentation technique [31]. Heattreated NiTi instruments are expected to perform better severely curved root canals and maintain original root canal anatomy with less procedural errors [32-34]. Therefore, the aim of the present study was to compare performance of 4 file systems with different heat treated NiTi alloy; M wire, CM wire, T wire and C wire, regarding transportation and centering ability in apical and middle thirds of severely curved root canals of extracted human teeth using CBCT scanning.

CBCT scanning was used as it is effective noninvasive imaging tool in evaluation of changes in dentin thickness and so detection of transportation and measuring centering ability [35-37].

Mesiobuccal root canals of extracted human mandibular teeth were used to evaluate performance of tested file systems in realis- tic conditions $[38,39]$, also these teeth are most frequently indicated for root canal treatment with many risk factors for procedural errors [40]. Crowns were maintained to mimic clinical conditions [41]. Evaluation was performed on four levels; 2,3,4 and $5 \mathrm{~mm}$ from the root apex representing the apical and middle thirds of root canal, in other words apical half in which preparation errors usually occur $[42,43]$.

To compare shaping ability of the four tested rotary systems, it was essential to have the same apical preparation diameter in all groups which was set to tip size $25[25,42,44]$. The systems used in the present study represent advancements in NiTi metallurgy via different heat treatment techniques producing different wires; M wire (PTN), CM wire (HFEDM), T wire (TS), C wire (OC).

In the present study there was no statistically significant difference in transportation and centering ratio at $2 \mathrm{~mm}, 3 \mathrm{~m}$ and $4 \mathrm{~mm}$ levels from apical foramen between the four systems, which might be attributed to no cutting tip design of all file systems used and standardized apical preparation size [45]. However, at $5 \mathrm{~mm}$ level; PTN caused highest median value of transportation $(0.15)$ which was statistically significant than other file systems. A possible explanation that; PTN X1 and X2 files have a progressive taper in their apical part which decreasing coronally, therefore produced highest value of transportation in the most coronal level $5 \mathrm{~mm}$ which was 
in accordance with other studies in which PTN produced higher transportation values coronal to curvature $[46,47]$.

Although PTN caused highest statistically significant value of transportation (0.15), this value was considered acceptable [28], and didn't exceed critical level of transportation (0.3) that may negatively affect clinical prognosis [48].

There was no statistically significant difference in centering ability between PTN and HFEDM at $5 \mathrm{~mm}$ level, which was statistically significantly lower than that of TS and OC systems, this might be because PTN X2 and HFEDM one file have similar apical taper about 0.08 [47] which larger than apical taper of TS and OC systems that have 0.06 fixed taper.

HFEDM, TS and OC recorded lowest median values of transportation with no statistically significant difference between them at any studied level. None of the four tested systems could produce perfectly centered preparation and as overall comparison between four systems regardless of root level there was no statistically significant difference between them. These results could not be compared with other studies as there is no previous published data have compared these 4 systems.

Therefore, based on these findings, the four evaluated file systems can be safely used in severely curved root canals without significant procedural errors.

\section{Conclusion}

Within limitation of the present study OC system showed promising performance in severely curved root canals which was comparable to HFEDM and TS systems and better than PTN.

\section{Conflict of Interest}

There is no any conflict of interest exists.

\section{Bibliography}

1. Schilder H. "Cleaning and shaping the root canal". Dental Clinics of North America 18.2 (1974): 269-296.

2. Ruddle C. "Cleaning and shaping the root canal system". In: Cohen S, Burns R, eds. Pathways of the Pulp, 8th edn. St Louis, MO: Mosby (2002): 231-292.

3. Hülsmann M., et al. "Mechanical preparation of root canals: shaping goals, techniques and means". Endodontic Topics 10.1 (2005): 30-76.
4. Bergmans L., et al. "Mechanical root canal preparation with NiTi rotary instruments: rationale, performance and safety". Status report for the American Journal of Dentistry 14.5 (2001): 324-333.

5. Glossen C R., et al. "A comparison of root canal preparations using Ni-Ti hand, Ni-Ti engine-driven, and K-Flex endodontic instruments". Journal of Endodontics 21.3 (1995): 146-151.

6. Park H. "A comparison of Greater Taper files, ProFiles, and stainless steel files to shape curved root canals". Oral Surgery, Oral Medicine, Oral Pathology, Oral Radiology, and Endodontics 91.6 (2001): 715-718.

7. Schäfer E and M Vlassis. "Comparative investigation of two rotary nickel-titanium instruments: ProTaper versus RaCe. Part 2. Cleaning effectiveness and shaping ability in severely curved root canals of extracted teeth". International Endodontic Journal 37.4 (2004): 239-248.

8. Gutmann J L and Y Gao. "Alteration in the inherent metallic and surface properties of nickel-titanium root canal instruments to enhance performance, durability and safety: a focused review". International Endodontic Journal 45.2 (2012): 113-28.

9. Haapasalo M and Shen Y. "Evolution of nickel-titanium instruments: from past to future". Endodontic Topics 29 (2013): 3-17.

10. Gambarini, Gianluca., et al. "Mechanical properties of a new and improved nickel-titanium alloy for endodontic use: an evaluation of file flexibility". Oral Surgery, Oral Medicine, Oral Pathology, Oral Radiology, and Endodontics 105.6 (2008): 798800.

11. Johnson Eugenia., et al. "Comparison between a novel nickeltitanium alloy and 508 nitinol on the cyclic fatigue life of ProFile 25/.04 rotary instruments". Journal of Endodontics 34.11 (2008): 1406-1409.

12. Alapati Satish B., et al. "Metallurgical characterization of a new nickel-titanium wire for rotary endodontic instruments". Journal of Endodontics 35.11 (2009): 1589-1593.

13. https://www.dentsplysirona.com/enae/explore/endodontics/protaper-next-rotary-files

14. Ruddle Clifford J., et al. "The shaping movement: fifth-generation technology”. Dentistry Today 32.4 (2013): 94, 96-99.

15. Elnaghy Amr M and Shaymaa E Elsaka. "Assessment of the mechanical properties of ProTaper Next Nickel-titanium rotary files". Journal of Endodontics 40.11 (2014): 1830-1834. 
16. Testarelli Luca., et al. "Bending properties of a new nickel-titanium alloy with a lower percent by weight of nickel". Journal of Endodontics 37.9 (2011): 1293-1295.

17. Shen Ya., et al. "Fatigue testing of controlled memory wire nickel-titanium rotary instruments". Journal of Endodontics 37.7 (2011): 997-1001.

18. https://global.coltene.com/pim/DOC/BRO/docbro684603-18-en-hyflex-cm-edm-a4senaindv1.pdf

19. Pirani C., et al. "HyFlex EDM: superficial features, metallurgical analysis and fatigue resistance of innovative electro discharge machined NiTi rotary instruments". International Endodontic Journal 49.5 (2016): 483-493.

20. Pedullà Eugenio., et al. "Torsional and Cyclic Fatigue Resistance of a New Nickel-Titanium Instrument Manufactured by Electrical Discharge Machining". Journal of Endodontics 42.1 (2016): 156-159.

21. h t t p s:// m i c ro-mega.com / w p c on tent/ uploads/2018/03/60301807-C_Brochure-2Shape_EN_WEB. pdf

22. ht t p s:// m i cro-mega.com/ w p c on tent/ uploads/2018/03/60301807-C_Brochure-Shape_EN_WEB. pdf

23. h t t p s : / / m i c r o-mega.com / w p - content/ uploads/2020/11/60301900-A_Flyer-One-Curve-PortfolioEN_web.pdf

24. https://micro-mega.com/wp-content/uploads/2020/06/ IFU_XLS_One_Curve-1.pdf

25. Razcha Christina., et al. "Micro-Computed Tomographic Evaluation of Canal Transportation and Centering Ability of 4 HeatTreated Nickel-Titanium Systems". Journal of Endodontics 46.5 (2020): 675-681.

26. Schneider S W. "A comparison of canal preparations in straight and curved root canals". Oral Surgery, Oral Medicine, And Oral Pathology 32.2 (1971): 271-275.

27. Gambill J M., et al. "Comparison of nickel-titanium and stainless steel hand-file instrumentation using computed tomography". Journal of Endodontics 22.7 (1996): 369-375.

28. Peters Ove A. "Current challenges and concepts in the preparation of root canal systems: a review". Journal of Endodontics 30.8 (2004): 559-567.
29. Weine FS., et al. "The effect of preparation procedures on original canal shape and on apical foramen shape". Journal of Endodontics 1.8 (1975): 255-262.

30. Glickman GN and Dumsha TC." Problems in canal cleaning and shaping". In: Gutmann JL, Dumsha TC, Lovdahl PE, Hovland EJ, eds. Problem Solving in Endodontics, 3rd edn. St Louis, MO: Mosby (1997): 91-122.

31. Burklein S and Schafer E. Critical evaluation of root canal transportation by instrumentation". Endodontic Topics 29 (2013): 110-124.

32. Yahata Y., et al. "Effect of heat treatment on transformation temperatures and bending properties of nickel-titanium endodontic instruments". International Endodontic Journal 42.7 (2009): 621-626.

33. Gambarini Gianluca., et al. "Mechanical properties of a new and improved nickel-titanium alloy for endodontic use: an evaluation of file flexibility". Oral Surgery, Oral Medicine, Oral Pathology, Oral Radiology, and Endodontics 105.6 (2008): 798800.

34. Johnson Eugenia., et al. "Comparison between a novel nickeltitanium alloy and 508 nitinol on the cyclic fatigue life of ProFile 25/.04 rotary instruments". Journal of Endodontics 34.11 (2008): 1406-1409.

35. Cotton Taylor P., et al. "Endodontic applications of cone-beam volumetric tomography". Journal of Endodontics 33.9 (2007): 1121-1132.

36. Michetti Jérôme., et al. "Validation of cone beam computed tomography as a tool to explore root canal anatomy". Journal of Endodontics 36.7 (2010): 1187-1190.

37. Arıcan Öztürk, Burçin., et al. "Cone-Beam Computed Tomographic Analysis of Shaping Ability of XP-endo Shaper and ProTaper Next in Large Root Canals". Journal of Endodontics 46.3 (2020): 437-443.

38. Shen Y and Cheung, G.S. (2013), Methods and models to study nickel-titanium instruments". Endodontic Topics 29 (2013): 18-41.

39. Berutti E and G Fedon. "Thickness of cementum/dentin in mesial roots of mandibular first molars". Journal of Endodontics 18.11 (1992): 545-548.

40. Wayman B E., et al. "Relative frequency of teeth needing endodontic treatment in 3350 consecutive endodontic patients". Journal of Endodontics 20.8 (1994): 399-401. 
41. Singh Shalini., et al. "Shaping Ability of 2Shape and WaveOne Gold Files Using Cone-Beam Computed Tomography". Journal of International Society of Preventive and Community Dentistry 9.3 (2019): 245-249.

42. Pinheiro S R., et al. "Evaluation of apical transportation and centring ability of five thermally treated NiTi rotary systems". International Endodontic Journal 51.6 (2018): 705-713.

43. American Association of Endodontics. Glossary of endodontic terms. 10th ed. Chicago: American Association of Endodontics (2020).

44. Bergmans L., et al. "Progressive versus constant tapered shaft design using NiTi rotary instruments". International Endodontic Journal 36.4 (2003): 288-295.

45. Hashem Ahmed Abdel Rahman., et al. "Geometric analysis of root canals prepared by four rotary NiTi shaping systems". Journal of Endodontics 38.7 (2012): 996-1000.

46. Wu Hui., et al. "Shaping ability of ProTaper Universal, WaveOne and ProTaper Next in simulated L-shaped and S-shaped root canals". BMC Oral Health 15 (2015).

47. Venino Pier Matteo., et al. "A Micro-computed Tomography Evaluation of the Shaping Ability of Two Nickel-titanium Instruments, HyFlex EDM and ProTaper Next". Journal of Endodontics 43.4 (2017): 628-632.

48. Wu M K., et al. "Leakage along apical root fillings in curved root canals. Part I: effects of apical transportation on seal of root fillings". Journal of Endodontics 26.4 (2000): 210-216.

\section{Assets from publication with us}

- Prompt Acknowledgement after receiving the article

- Thorough Double blinded peer review

- Rapid Publication

- Issue of Publication Certificate

- High visibility of your Published work

Website: www.actascientific.com/

Submit Article: www.actascientific.com/submission.php

Email us: editor@actascientific.com

Contact us: +919182824667 